\title{
O centenário de uma riqueza cultural: festa de São Sebastião em Jarilândia, distrito de Vitória do Jari/Amapá
}

\author{
The centenary of a cultural richness: celebration of São \\ Sebastião in Jarilândia, district of Vitória do Jari / Amapá
}

\author{
PIEDADE LINO VIDEIRA ${ }^{\mathrm{a}}$ \\ ELIVALDO SERRÃo Custódiob \\ ELIVELTON INAJOSA DA SILVAc
}

LUÃ BUENO ALHO

\section{Resumo}

Este estudo aborda o Centenário de uma riqueza cultural: a festa de São Sebastião em Jarilândia, distrito de Vitória Do Jari/Amapá. O estudo, numa perspectiva geral, visa analisar a importância da Festa de São Sebastião para a comunidade de Jarilândia. Tratase de uma pesquisa de campo de abordagem qualitativa e descritiva com a colaboração de moradores mais antigos da comunidade. Foram utilizados como instrumentos de coleta de dados a análise de documentos, questionários e entrevistas. Os resultados indicam que o Distrito de Jarilândia apresenta características culturais e religiosas peculiares, em um contexto amazônico: elementos de origem africana no tocar de seus instrumentos, na récita de ladainhas de herança católica, com culinária e modos próprios de festejar.

Palavras-chave: Religiosidade. Festa de São Sebastião. Jarilândia. Patrimônio Cultural. Amapá.

\footnotetext{
a Universidade Federal do Amapá (UNIFAP), Macapá, Brasil. Doutora em Educação, e-mail: piedadevideira@bol.com.br

b Universidade Federal do Amapá (UNIFAP), Macapá, Brasil. Doutor em Teologia, com PósDoutorado em Teologia, e-mail: elivaldo.pa@hotmail.com

c Universidade Federal do Amapá (UNIFAP), Macapá, Brasil. Pedagogo, e-mail: piedadevideira@bol.com.br

d Universidade Federal do Amapá (UNIFAP), Macapá, Brasil. Bacharel em Teologia e Especialista em Educação, e-mail: piedadevideira@bol.com.br
} 


\section{Abstract}

This study presents as theme The Centenary of a cultural richness: feast of St. Sebastian in Jarilândia, district of Vitória Do Jari / Amapá. The study, from a general perspective, aims to analyze the importance of the Feast of St. Sebastian for the community of Jarilândia. This is field research with a qualitative and descriptive approach with the collaboration of older residents of the community. Analysis of documents, questionnaires, and interviews were used as instruments of data collection. The results indicate that the District of Jarilândia presents peculiar characteristics of its culture, in an Amazon context: elements of African culture in the playing of its instruments, in the way of celebrating, in the litanies and in the cooking.

Keywords: Religiosity. Jarilândia. Celebration of San Sebastian. Cultural heritage. Amapá

\section{Introdução}

Quantas vezes muitos de nós nos sentamos ao colo de nossos avós para nos deleitar com diversas histórias, fazendo mil perguntas e rindo das situações engraçadas vividas por nossos pais e familiares? Essa prática é um ato relevante de afetividade, mas também uma maneira de salvaguardar o passado e as origens de inúmeros povos. Saber de onde nossos antepassados vieram, como surgiram os primeiros habitantes de determinado lugar, como se relacionavam, como dançavam, como se comunicavam com as forças espirituais, dentre outros fatos, é fundamental para a construção de uma identidade.

Neste contexto, esta pesquisa tem como objeto a festa de São Sebastião, no distrito de Jarilândia, município de Vitoria do Jari, no estado do Amapá que acontece no mês de janeiro, entre os dias 10 e 20. No ano de 2016, o festejo completou cem anos de existência. Diante deste cenário, o presente estudo pretende mostrar aspectos a respeito da origem, bem como a relevância do evento, para a valorização e salvaguarda da cultura amapaense em Jarilândia, AP.

Partimos do pressuposto de que, conforme as gerações vão se passando, as tradições, crenças e costumes de um povo, que não se atenta para a salvaguarda de sua história, vão se apagando. Portanto, o objetivo que se apresenta nesta investigação é de analisar a importância da Festa de São 
Sebastião para a comunidade de Jarilândia, bem como identificar os elementos constitutivos desse festejo a partir dos relatos dos moradores mais antigos ${ }^{1}$ a fim de suscitar a relevância desse evento para a proteção e valorização da cultural regional e local.

A pesquisa se organiza em três seções:

- A primeira detalha os caminhos e procedimentos metodológicos da pesquisa, apresentando as bases conceituais e teóricas sobre cultura e patrimônio. Nesta seção é apresentado também o recorte espacial que será aprofundado posteriormente.

- Na segunda seção apresenta-se as considerações sobre o estudo realizado com os antecedentes históricos do distrito de Jarilândia e, ainda, informações a respeito da origem deste, ao abordar os primeiros habitantes e descrever as atividades atuais da Vila de Jarilândia.

- Na terceira e última seção, por sua vez, aborda-se a Festa de São Sebastião para contextualizar sua origem que completou em 2016 cem anos de existência. Abordamos também os personagens marcantes dessa trajetória e os atos da festa que se estende durante dez dias do mês de janeiro.

Por fim, apresentam-se as considerações finais.

\section{Caminhos e procedimentos metodológicos da pesquisa}

A presente seção está estruturada para explicar o conjunto de procedimentos metodológicos utilizados na realização deste trabalho. De natureza qualitativa, os métodos ajudaram-nos a perceber criticamente a realidade investigada e interpretá-la.

Maria Marly de Oliveira, sobre a pesquisa qualitativa, expressa que esta é [...] um processo de reflexão e análise da realidade através da utilização de métodos e técnicas para compreensão detalhada do objeto de estudo em seu contexto histórico

\footnotetext{
${ }^{1}$ A realização da coleta de dados sobre a Festa Centenária de São Sebastião ocorrida no Distrito de Jarilândia - Município de Vitória do Jari, no Estado do Amapá foi realizada através de depoimentos orais, mediante atendimento das recomendações previstas na Resolução n. 466/2012 do Conselho Nacional de Saúde que visa assegurar a vontade dos entrevistados/colaboradores em contribuir e permanecer, ou não, na pesquisa, por intermédio de manifestação expressa, livre e esclarecida.
} 
e/ou segundo sua estruturação"2 . Portanto, deverá contribuir para o reconhecimento, a valorização e a salvaguarda do patrimônio histórico-cultural presente na Festa de São Sebastião, realizada no distrito de Jarilândia, município de Vitória do Jari.

Esta investigação foi realizada na comunidade do distrito de Jarilândia, localizada no município de Vitória do Jari (165.12 km de Macapá), às margens do Rio Jari, extremo Sul do estado do Amapá. A população de Vitória do Jari perfaz o quantitativo de 12.428 pessoas, segundo o Instituto Brasileiro de Geografia e Estatística (IBGE) ${ }^{3}$ possui uma área de $2.483 \mathrm{~km}^{2}$, o que resulta numa densidade demográfica de 4,44 hab/km².

Em Jarilândia vivem cerca de 920 pessoas pertencentes às famílias que migraram no período da seringa e da castanha e que ficaram na Vila mesmo após a saída da empresa Jari Celulose S.A., e hoje sobrevivem da agropecuária, do serviço público e do comércio. Em Jarilândia reside uma comunidade formada por famílias tradicionais. Elas são responsáveis pelo festejo de São Sebastião há mais de três gerações.

Ou seja, são famílias que foram e fazem parte dos primeiros moradores da Vila de Jarilândia.

Essas famílias construíram e repassaram a seus membros uma bagagem cultural, que não se limita ao conhecimento empírico adquirido ao longo dos anos sobre a vila e a festa de São Sebastião. Notadamente encontra-se um acervo pessoal vivo e dinâmico sobre a comunidade jarilandiense, especificamente a respeito da festa, em que esse acervo se encontra salvaguardado nas memórias dos moradores, em fotografias e objetos que a identificam.

Tal expressão cultural mobiliza grande parte dos moradores e atrai muitos visitantes no período de 10 a 20 de janeiro, o que faz desta festa a maior celebração cultural de Jarilândia, agregando elementos da cultura portuguesa, de cunho católico e da cultura afrodescendente.

Nas palavras de Peter Burke encontramos na constituição da festa um verdadeiro encontro intercultural ${ }^{4}$. Pois, durante o festejo, a partir da veneração ao santo, são desempenhadas várias atividades dentro da

\footnotetext{
2 OLIVEIRA, M. M. Como fazer pesquisa qualitativa. 2. ed. Petrópolis: Vozes, 2008. p. 37.

${ }^{3}$ BRASIL. Instituto Brasileiro de Geografia e Estatística (IBGE). Censo Populacional 2010. Disponível em <https://www.ibge.gov.br/>. Acesso em: 11 nov. 2015.

${ }^{4}$ BURKE, P. Hibridismo Cultural. São Leopoldo: Ed. Unisinos, 2006.
} 
comunidade, de cunho religioso e sociocultural, que englobam questões afrodescendentes, uma vez que a presença africana é presenciada nos tambores do festejo, nas ladainhas, no cortejo do santo, nas nomenclaturas de origem africana como cuscuz e canjica, nas iguarias que são comercializadas. Tudo isso dentro de um contexto amazônico-amapaense.

Para esta pesquisa buscamos compreender os sentidos e explicar os símbolos e seus significados, com base no pensamento do antropólogo Clifford Geertz quando diz que:

O homem é um animal amarrado a teias de significados que ele mesmo teceu, assumo a cultura como sendo essas teias e a sua análise; portanto, não como uma ciência experimental em busca de leis, mas como uma ciência interpretativa, à procura do significado 5 .

O propósito é dar suporte à população local, para que reconheçam a festividade de São Sebastião como elemento da sua identidade, atrelada à cultura. E, ainda, possam entender os significados que já foram atribuídos a eles ao longo do tempo em decorrência do evento, já que a festividade é cultura viva desse povo e, por sua vez, é tecida por identidades plurais e intergeracional repassada às futuras gerações através da dinâmica das narrativas orais dos moradores mais velhos da comunidade.

A partir do entendimento conceitual que tivemos sobre os procedimentos teóricos e metodológicos fundamentais para o desenvolvimento dessa modalidade de pesquisa qualitativa, despertou-nos a atenção para o inventário. Ele se baseia na busca de informações referentes à festa de São Sebastião e formulação de material físico a respeito do festejo. Material esse que se faz necessário quando se trata de reconhecimento e registro do patrimônio cultural imaterial, que foi classificado para esta pesquisa como representações, expressões, conhecimento, técnicas envolvidas com instrumentos, objetos e artefatos utilizados no espaço cultural da festa de São Sebastião, que abrange a comunidade de Jarilândia.

Destacamos a importância do inventário com a finalidade de prevenir que esse patrimônio venha a ser descaracterizado ou destruído. Para tanto, se

\footnotetext{
${ }^{5}$ GEERTZ, C. A interpretação das culturas. Rio de Janeiro: LTC, 2013. p. 4.
} 
faz necessário uma ação integrada de salvaguarda, proteção, cuidado e promoção da festa de São Sebastião com a gerência compartilhada entre a comunidade de Jarilândia e o Estado brasileiro através de suas instituições que atuam no campo da preservação do patrimônio Cultural.

Face ao exposto, utilizamos ainda o método da Pesquisa Descritiva com o intuito de dar ênfase à manifestação cultural jarilandiense, para não perder informações importantes que representam esse patrimônio histórico-cultural vivo e dinâmico contido em cada morador da comunidade, e posteriormente interpretar os fenômenos encontrados.

Percebemos ainda que para descrever a festa de São Sebastião e obter dados, era preciso a participação da comunidade, pois eles são sujeitos do conhecimento empírico e cultural desse festejo. Portanto, também utilizamos a Pesquisa Participante a fim de analisar em conjunto com a comunidade a realidade dela, a partir da festa de São Sebastião, e entender os motivos que a fazem tão grandiosa. Nesse sentido buscamos, não apenas registrar o que dizem as memórias dos moradores da comunidade de Jarilândia sobre a festa, mas permitir que eles participassem com suas indagações e inquietações.

Para a realização deste estudo optamos inicialmente em selecionar moradores da comunidade, em seguida classificamos aqueles moradores que já tiveram ou ainda têm relação com o objeto de investigação: a festividade, com o intuito de coletar melhores informações. Assim foi possível obter narrativas mais detalhadas sobre a festa de São Sebastião. Os colaboradores foram identificados a partir de uma sondagem para classificar os moradores mais antigos com média de idade entre 59 a 89 anos. Essa seleção se fez necessária para obtenção de melhores informações sobre o festejo, uma vez que falamos de uma festa centenária e buscamos suas raízes, para então entendê-la e interpretar seus significados.

Para tanto, é preciso reconhecer que os moradores mais antigos vivenciaram os primeiros passos dessa festividade. Buscamos também identificar as pessoas que estão ligadas à atual coordenação da Festa, por considerar que elas possuem dados mais atuais sobre o evento. Os moradores mais velhos na grande maioria são aposentados e estão na faixa etária de 59 a 89 anos de idade, são ex seringueiros, agricultores, domésticas, pais de muitos filhos e ex-coordenadores do festejo. 
Já na atual coordenação da festa estão à frente pessoas residentes na comunidade, como a senhora Regiovane Silva (43 anos). Eles recebem o apoio de apreciadores da festa, que são de outras localidades, principalmente de Santana e de Macapá. Apresentamos a seguir um quadro com os colaboradores do estudo:

Quadro 1 - Moradores mais antigos de Jarilândia

\begin{tabular}{|c|c|}
\hline Nome do morador/a & Bibliografia \\
\hline Moacir Gomes Caldas (82 anos) & $\begin{array}{l}\text { Um dos moradores mais antigos da Vila de Jarilândia, mora } \\
\text { com seu neto, pois os filhos moram em outras cidades. Tem } \\
\text { um sítio onde produz açaí, pupunha, banana e cacau. Seu } \\
\text { depoimento foi coletado } 25 \text { de fevereiro de 2015, na } \\
\text { residência dele. }\end{array}$ \\
\hline Antônio Vicente (75 anos) & $\begin{array}{l}\text { Veio do município de Afuá-PA do Rio Baturité, em 1953. É } \\
\text { produtor de açaí e tem um comércio. Ele e a esposa, Dária, } \\
\text { foram coordenadores da Festa de São Sebastião. A } \\
\text { entrevista foi realizada em } 26 \text { de fevereiro de } 2015 \text {, também } \\
\text { na residência dele. }\end{array}$ \\
\hline Agostinho Góes da Silva (80 anos) & $\begin{array}{l}\text { Foi por muitos anos o devoto que balançava a bandeira de } \\
\text { São Sebastião. Teve } 11 \text { filhos com a esposa, dona Cléia. } \\
\text { Infelizmente, três meses depois da entrevista, ele faleceu. A } \\
\text { conversa foi realizada em } 25 \text { de fevereiro de } 2015 \text {, na } \\
\text { residência da família dele. }\end{array}$ \\
\hline Helena da Costa Tavares (87 anos) & $\begin{array}{l}\text { Nasceu no lgarapé do Bituba. O pai dela era cearense e a } \\
\text { mãe paraense. Mãe de três filhos, é a moradora mais velha } \\
\text { da vila. Personagem marcante na Ponte do Bacabal, pois } \\
\text { com um cachimbo, deita em uma rede e olha a } \\
\text { movimentação das pessoas que passam em frente a casa } \\
\text { dela. A entrevista com Tia Helena foi em } 26 \text { de fevereiro de } \\
2015 \text {. }\end{array}$ \\
\hline $\begin{array}{l}\text { Raimundo de Oliveira Barreto } \\
\text { (70 anos) }\end{array}$ & $\begin{array}{l}\text { Nasceu também no Igarapé do Bituba, mora na Ponte do } \\
\text { Bacabal, em Jarilândia, na última casa. A entrevista com Seu } \\
\text { Salvador, como é chamado, foi em } 26 \text { de fevereiro de } 2015 \text {. }\end{array}$ \\
\hline Jesuína Bueno Neves (66 anos) & $\begin{array}{l}\text { Esposa do Seu Dico Felix é uma das vozes marcantes que } \\
\text { entoam a ladainha do padroeiro. É a moradora atual da casa } \\
\text { que pertenceu aos portugueses. A entrevista foi realizada } \\
\text { em } 5 \text { de julho de 2015, em Jarilândia. }\end{array}$ \\
\hline $\begin{array}{l}\text { Francisco da Conceição Alho (68 } \\
\text { anos) }\end{array}$ & $\begin{array}{l}\text { Mora no rio Acaraquiçaua. É fazendeiro da região. Viúvo da } \\
\text { Sra. Magá, como era chamada a esposa dele, juntos criaram } \\
\text { seis filhos na fé católica. Atualmente ajudam na organização } \\
\text { da festa, junto com os filhos, ou seja, netos de Francisco. A } \\
\text { entrevista foi realizada na Fazenda Estrela do Norte em } 06 \\
\text { de julho de } 2015 \text {. }\end{array}$ \\
\hline
\end{tabular}

Fonte: Dados recolhidos em entrevistas. 
Nesta pesquisa utilizamos meios para que fosse possível analisar e compreender a relação da comunidade com a Festa de São Sebastião: a) Análise de documentos: buscamos informações em documentos que ainda não tinham sido analisados. Trata-se de material encontrado com os moradores, documentos estes classificados como cartas, pareceres, fotografias, relatórios, diários, vídeos, panfletos, folhas de hinos, discursos, depoimentos orais e escritos, que são fundamentais para a pesquisa em questão; b) Formulários: foram utilizados para atender aos objetivos do estudo. Construímos um roteiro de perguntas para que nossos sujeitos pudessem responder e interagir conosco. Isso nos permitiu respostas mais fiéis em relação ao que pretendíamos investigar, isto é, a festa de São Sebastião, apreciando a fala, os gestos e as expressões dos colaboradores; c) Entrevista: esse instrumento serviu como meio de interação e informação detalhada entre o pesquisador e o entrevistado. Assim, por intermédio desse instrumento, foi possível perceber as sensações que cada entrevistado transmitia ao relatar sobre a festa de São Sebastião e a sua relevância para a comunidade, o que trouxe maior fidelidade aos fatos contados.

\section{Principais conceitos e definições usados na pesquisa}

A festa de São Sebastião é caracterizada pela sua simplicidade e irreverência no Vale do Jari. É distante dos holofotes da mídia nacional, das grandes estruturas de eventos que suportam milhares de expectadores. O festejo é um evento cultural, que no contexto macro, passava despercebido no estado do Amapá, mas é reconhecido pela comunidade local e pelos apreciadores da tradição cultural centenária.

Assim, a festa de São Sebastião, cheia de conteúdos simbólicos construídos por crenças, costumes, valores e religião, é uma tradição cultural que passou de pai para filho através da oralidade. Neste cenário em que se consideram os que participam ativamente do desenvolvimento do festejo, ressaltamos a relação das famílias tradicionais da Vila, pois elas são fundamentais para a continuidade da tradicional festividade. Para o estudo em questão utilizamos conceitos que foram primordiais para a construção desta pesquisa. 


\section{Cultura}

Entendemos a cultura como uma teia de significados que o ser humano constrói, em que cada fio dessa teia é essencial para a construção da identidade cultural do indivíduo e de seu grupo ${ }^{6}$. Assim se forma um conjunto de signos que inclui conhecimentos, crenças, arte, moral, leis, costumes ou qualquer outra capacidade ou hábitos adquiridos pelo homem como membro de uma sociedade. Isto fundamenta o conceito de cultura utilizado neste trabalho.

Além dele utilizamos outro, definido por Roque de Barros Laraia de que a Cultura é tudo aquilo produzido pela humanidade que tenha um significado, seja no plano concreto ou no plano imaterial. Por isso, "não existe ser humano sem cultura, sem um complexo de conhecimentos e de habilidade humana empregada socialmente"7. Desses conceitos macros de cultura, partimos para uma descrição mais densa, usando como fundamento teórico a leitura semiótica de Clifford Geertz ${ }^{8}$. Segundo este autor, o ser humano encontraria sentido nos acontecimentos por meio dos quais ele vive, por intermédio de padrões culturais.

Assim, buscamos no ponto de vista de Clifford Geertz, uma visão para "auxiliarnos a ganhar acesso ao mundo conceptual no qual vivem os nossos sujeitos, de forma a podermos, num sentido um tanto mais amplo, conversar com eles" 9 . Essa abordagem mostrou-se pertinente quando interpretamos os significados sobre a cultura local de Jarilândia correlacionados à festividade de São Sebastião. Neste sentido, também buscamos em Roque Laraia interpretações que demonstram que o comportamento dos indivíduos depende de um aprendizado, de um processo denominado endoculturação ${ }^{10}$. Quando a criança incorpora as normas de uma sociedade, podemos dizer que ela se endocultura, ou seja, assimila, incorpora, absorve a maneira de pensar, agir, sentir, própria da cultura em que nasceu.

\footnotetext{
${ }^{6}$ GEERTZ, 2013.

${ }^{7}$ LARAIA, R. de B. Cultura: Um conceito antropológico. 14a ed. Rio de Janeiro: Jorge Zahar, 2001, p. 38.

8 GEERTZ, 2013

${ }^{9}$ GEERTZ, 2013, p. 17.

10 LARAIA, 2001.
} 


\section{Patrimônio}

A necessidade de trabalhar o patrimônio cultural no meio social fortalece a relação das pessoas com suas heranças culturais. A Constituição Federal de 1988 em seu Artigo 216 nos diz que “constituem patrimônio cultural brasileiro os bens de natureza material e imaterial, tomados individualmente ou em conjunto, portadores de referência à identidade, à ação, à memória dos diferentes grupos formadores da sociedade brasileira, nos quais se incluem".

Para a presente pesquisa, o patrimônio cultural de Jarilândia é representado pela Festa de São Sebastião. Percebemos, então, que a festa se insere no conceito de Patrimônio Imaterial. A partir deste conceito de patrimônio, a festa centenária de São Sebastião constitui-se em Patrimônio Imaterial do estado do Amapá, e, na relação com as manifestações da cultura popular e a noção de patrimônio o Estado precisa promover iniciativas que possam viabilizar a guarda de memórias de expressões culturais.

No intuito de traçar um caminho para a formação cultural, para a execução desta pesquisa, fomos a campo em busca dessas experiências e histórias; para apresentar a história de Jarilândia, de acordo com o relato dos sujeitos deste estudo citados acima.

\section{Festa de São Sebastião: o santo padroeiro do rio Jari}

O objetivo desta seção é descrever a origem da Festa de São Sebastião e identificá-la dentro da história de Jarilândia, bem como compreender seus significados e sequência de cada etapa da festa. Segundo Raymundo Heraldo Maués e Célia Guimarães Vieira a concepção a respeito dos santos é a de pessoas que viveram neste mundo e, por processos diversos, se santificaram após a morte. Está presente a ideia de pessoas que, durante a vida, praticaram o bem, seguiram os ensinamentos de Cristo e se orientavam nas doutrinas católicas ${ }^{10}$.

\footnotetext{
${ }^{10}$ MAUÉS, R. H.; VIEIRA, C. G. et al. (Orgs.). Diversidade biológica da Amazônia. Belém, Museu Paraense Emílio Goeldi, 2001, pp. 253-272.
} 
Nesse sentido, inúmeros santos do catolicismo são venerados no Brasil, como: Nossa Senhora de Aparecida (Padroeira do Brasil); os santos juninos (Santo Antônio, São João, São Pedro e São Marçal, festejado em todo Brasil, mas principalmente no nordeste); Nossa Senhora de Nazaré (cuja festa é realizada em diversas cidades da Amazônia, com a maior delas em Belém do Pará), entre outros.

A diversidade de santos celebrados no país reflete a ideia de "dimensões continentais", retratada por Piedade Lino Videira (2009, p. 256):

\begin{abstract}
Nesse sentido o que especifica as características regionais de cada um desses grupos sociais espalhados por esse país de dimensões continentais são as expressões socioculturais e constituições histórica e econômica predominante em cada região e estado. Para entender a diversidade de expressões culturais e artísticas brasileiras é preciso, antes, conhecer o povo brasileiro, mediante suas singularidades expressas em suas manifestações culturais, religiosas e regionais ${ }^{11}$.
\end{abstract}

Sendo assim, partindo desse cenário nacional, observamos que no estado do Amapá, comemoram-se as festas de São José, em Macapá; São Tiago, no município de Mazagão; Santa Ana, em Santana; Santo Antônio, em Laranjal do Jari; São Benedito, em Macapá e em Santana, São Pedro, em Pedra Branca; e Nossa Senhora do Brasil, em Porto Grande. Destaca-se também a Festa do Divino Espírito Santo e da Santíssima Trindade - festejados no ciclo do Marabaixo — realizada anualmente em Macapá, nos bairros urbanos Laguinho e Favela, este último, hoje nomeado Santa Rita. Nesse contexto amapaense, destacamos nesta pesquisa os Festejos de São Sebastião, em Jarilândia (distrito de Vitória do Jari, extremo sul do Amapá).

Ao se retratar Jarilândia, consequentemente deve-se mencionar a festa de São Sebastião. O santo, para a igreja católica, é considerado um soldado de Cristo, pois foi flagelado em uma laranjeira por se considerar cristão. Sebastião era do exército romano, considerado um dos oficiais prediletos do Imperador Diocleciano ${ }^{12}$.

\footnotetext{
${ }^{11}$ VIDEIRA, P. L. Marabaixo dança afrodescendente: significando a identidade étnica do negro amapaense - Fortaleza: Edições UFC, 2009. p. 256.

${ }^{12}$ Novena de São Sebastião. In: Paullus, 1998.
} 
Sebastião fazia tudo para ajudar os irmãos na fé. Por isso tentava revelar o Deus verdadeiro aos soldados e aos prisioneiros. Secretamente, conseguiu converter muitos pagãos ao cristianismo, e em certa ocasião, foi denunciado e não negou sua fé perante o Imperador que tanto o admirava. Este mandou o oficial escolher entre o cargo no exército e a sua fé em Cristo. Por defender sua fé, Sebastião foi vítima da intolerância cristã. Foi atingido por flechadas e logo depois, morto a pauladas.

Figura 1 - Imagem de São Sebastião de Jarilândia

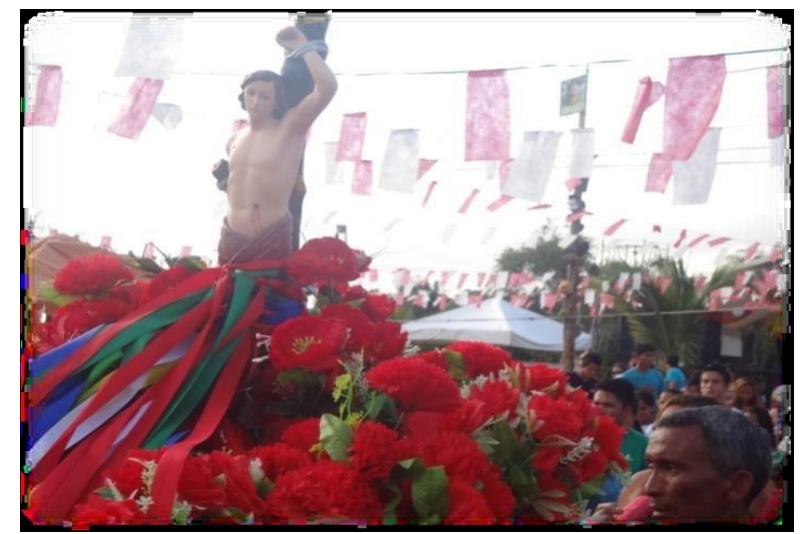

Fonte: Luã Alho (2012).

A partir daí, São Sebastião passou a ser um exemplo de fidelidade à fé cristã, e logo passou a ser venerado por devotos em diversos lugares no mundo. Um desses lugares é Jarilândia.

\section{A origem da festa em Jarilândia}

A festa de São Sebastião é uma demonstração de fé que surgiu e cresceu junto à história de Jarilândia. Como foi apresentado no capítulo anterior, a Vila foi primeiramente chefiada pelo cearense Zé Júlio, ocupando-a com seus trabalhadores, entre negros e pardos. Depois vieram os portugueses, e por último, os americanos. Cada um deixou sua marca nessa terra. Então, no período em que o coronel Zé Júlio era o administrador das terras de todo o Vale do Jari, surgiu a festa de São Sebastião em Jarilândia. A história começou em 
uma região chamada Limão (atualmente Fazenda Nova Jerusalém), que foi a primeira sede das terras do Coronel José Júlio.

Naquele período, todo o Vale do Jari enfrentava uma epidemia de gripe que estava matando muitas famílias. Segundo Helena Tavares, 87 anos, "diziam que morriam igual formiga". Foi então que Dona Francisca, esposa de Zé Angélico (Gerente do Coronel), muito católica, assim como grande parte dos que lá habitavam, fez uma promessa a São Sebastião. Ela clamou ao santo para que a epidemia não chegasse à região que residia. Em troca, mandaria buscar uma imagem em agradecimento pela graça alcançada, para que fosse homenageado anualmente.

A epidemia cessou e a promessa precisava ser cumprida, foi então que, no ano de 1916, dona Francisca, realizou a primeira festa em homenagem a São Sebastião, ainda na região do Limão. Conforme afirma a senhora Helena (87 anos), "- São Sebastião foi colocado como padroeiro do Rio Jari, e não só de Jarilândia. As outras pessoas que falam que é Santo Antônio, mas o Padroeiro do Rio Jari é São Sebastião, por causa da promessa da Francisca".

A devoção então começou, o respeito e os agradecimentos pela intercessão do Santo se concretizavam em uma festa ao longo de dez dias do mês de janeiro. A festa era animada, segundo Sebastião Tavares ${ }^{13}$ (74 anos), por um grupo de pessoas que tocavam tambores, pandeiros, chocalhos que se preparavam a ramada". Logo depois "um grupo lá do Aruans ${ }^{14}$ vinha tocar todo ano e assim a festa era animada".

O senhor Antônio Vicente (75 anos) contou outros detalhes sobre a história:

Dona Francisca, era uma morena, mulher do Zé Angélico. Trouxe a imagem do santo dentro de uma maleta. Fizeram primeiro uma ramada e logo depois deu início a festa. Passados dez anos da festa lá no Limão, o gerente Seu Aguiar viu as terras de Jarilândia e achou que era melhor a sede da administração de Zé Júlio vir pra cá. Aí fizeram um comércio, a capela e uma casa, ai depois começou a festa aqui. Quando o Seu Aguiar foi embora, veio a Dona Oscarina, mulher do Sales, irmão do Zé Sirico. Ela ficou a mais

\footnotetext{
${ }^{13}$ Sebastião Tavares, de 74 anos, foi coordenador da festa de são Sebastião. Atualmente é agente distrital.

${ }^{15}$ Festa no salão ao som dos tambores.

${ }^{14}$ Localidade que se localiza no Rio Amazonas.
} 
de dez anos gerenciando a festa. [...]. Os padres vinham do Xingú pra fazer a festa, depois que passou pra diocese de Santarém, os padres vinham de Santarém.

[...] a igreja era na beira do rio, aqui confronte de casa, jogaram pra lá e combinaram que a igreja do São Sebastião tinha que ficar no centro da cidade.

Com o passar dos anos, conforme o relato acima, a festa de São Sebastião foi crescendo e a cada ano se tornando uma tradição mais fortalecida. Assim, em 2016, completou cem anos. Graças à fé e à tradição desse povo, o centenário do festejo aconteceu com intensa participação da comunidade e de pessoas que nasceram no lugar, que no período da celebração retornam para saudar o santo de devoção, além de outros que queriam conhecer a festa. Ressaltamos, ainda, que os devotos de São Sebastião que iniciaram essa centenária trajetória de fé cristã, foram lembrados em homenagem póstuma.

\section{Devotos, romeiros e foliões}

Várias foram as pessoas que contribuíram para o centenário da festa de São Sebastião. Desde a Dona Francisca até a atual coordenadora da festa, a senhora Regiovane Silva (43 anos). As famílias citadas no segundo capítulo, ainda possuem representatividade na organização do festejo. Seja ela na ornamentação, no reparo da igreja, na queima de fogos, na parte de sonorização, na divulgação e em outros serviços.

Os devotos de São Sebastião - nome dado àqueles que têm o Santo como padroeiro, em busca de melhores condições de vida, com o passar do tempo, foram se espalhando por diversas cidades, dentre elas: Santana, Macapá, Laranjal do Jari, Vitória do Jari, Monte Dourado, Belém, dentre outras. Porém, esses devotos se planejam durante o ano para que em janeiro possam voltar à Jarilândia, em caravanas, para celebrar a festa do padroeiro. 
Figura 2 - Chegada dos Romeiros das Cidades

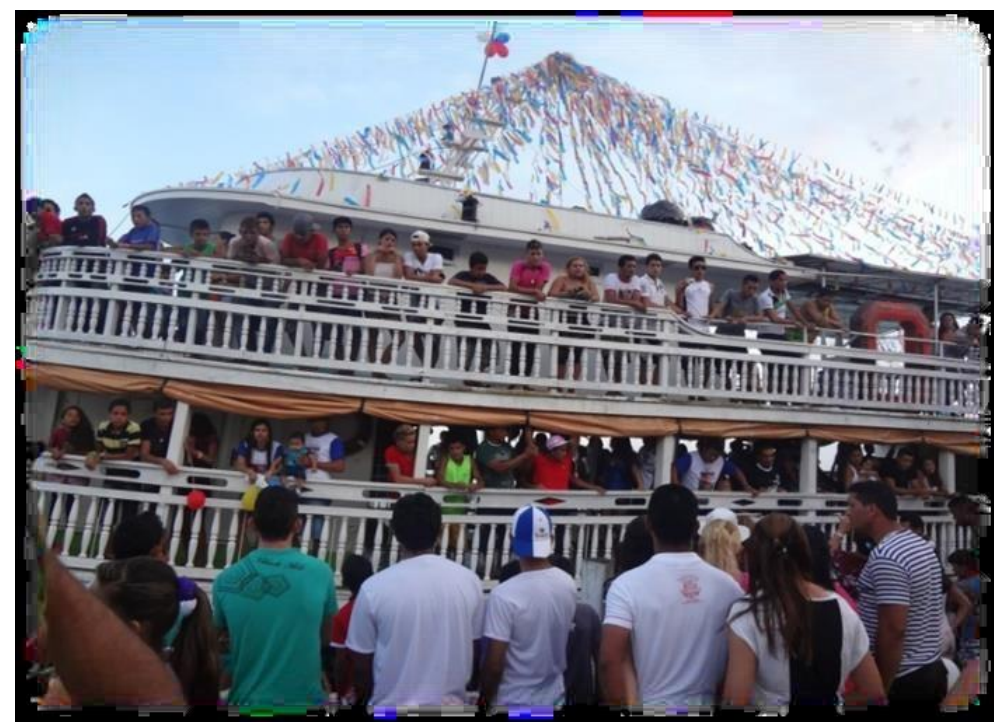

Fonte: Luã Alho (2012).

Quando esses romeiros chegam, são recebidos com muita alegria pelos devotos que ainda habitam na Vila. Quando possível, a equipe dos foliões de São Sebastião (os animadores) levam a bandeira e a imagem do padroeiro até o porto para cantar e receber os romeiros que, emocionados ao olhar, lembram-se de toda uma vivência repleta de significados.

A respeito desse sentimento de pertencimento a uma cultura, Stuart Hall diz que: "possuir uma identidade cultural nesse sentido é estar primordialmente em contato com um núcleo imutável e atemporal, ligando ao passado o futuro e o presente numa linha ininterrupta" ${ }^{15}$. Esse cordão umbilical é o que chamamos de tradição, a qual segue em plena atualização face a dinâmica inerente às culturas e seus processos de gerenciamento, que agem numa outra lógica temporal e cotidiana, sem tanta pressa como vemos na contemporaneidade. Tal característica é benéfica às culturas tradicionais e conferem significado às nossas vidas e dão sentido à nossa história.

A tradição, conforme expressa ainda Stuart Hall, é o cordão umbilical, que nos remete a uma viagem no tempo. Do mesmo modo, faz com que os devotos, romeiros e foliões de São Sebastião se unam para celebrar a fé e perseverar a festa centenária do padroeiro do Rio Jari ${ }^{18 .}$

\footnotetext{
${ }^{15}$ HALL, S. A identidade cultural na pós-modernidade. 7. ed. Rio de Janeiro: DP\&A, 2002, p. 29.

18 HALL, 2002.
} 


\section{Atos da festa religiosa}

A comunidade paroquial indica o coordenador da comunidade, que durante dois anos realiza as atividades da igreja, e que no mês de dezembro já começa a planejar toda a festa, desde a ornamentação da igreja, até a contratação do som para a festa social. Atualmente quem assumiu a coordenação da comunidade no ano de 2015 e 2016 foi a senhora Regiovane Silva (43 anos), ela e sua equipe desempenham atividades na igreja, cada pessoa em um setor, como: a liturgia, o financeiro, o bar, dentre outros.

Essa equipe, junto com os Juízes da Festa (nomenclatura atribuída para aqueles que assumiram o compromisso de realizar a festa ao desamarrar os nós da bandeira central no último dia do evento), tem a responsabilidade de realizar os festejos de São Sebastião.

\section{A peregrinação "Esmola"}

O período da festa de São Sebastião é de 10 a 20 de janeiro, porém, antes desses dez dias e, especialmente no dia 18, a equipe dos Foliões de São Sebastião, composta por jovens da comunidade e chefiada pela dona Maria dos Anjos Neves (66 anos) ${ }^{16}$, seguem uma longa jornada. Ela sai de Jarilândia, geralmente, no dia 2 de janeiro, para realizar a Esmola de São Sebastião.

O grupo parte em uma embarcação levando a imagem do padroeiro para as comunidades da foz do Rio Jari, com o Rio Amazonas (Maracujá, Maruim, Laranjal, Aruãns, Santa Rosa, Jardim do Edem, Furo Grande, Limão, Tartaruguinha, Santana do Flechal, Bacabal, Aturiá e Cajuzinho), bem como para as comunidades localizadas em Jarilândia, acima do Rio Jari, a exemplo de Saudade, Bezerra, Tucunarei, Binga, Chavie, Marajó, Polônia, Açaízau, Paga Dívida e Bom Jardim"

\footnotetext{
${ }^{16}$ Agente de conservação da Escola Estadual Jarilândia, conhecida como Maria do Carlito - apelido do marido, Carlos Valente Neves (68 anos).

${ }^{17}$ Fonte: Ezau Neves e Caroline Neves, foliões e filhos de D. Maria e Carlito.
} 
Figura 3 - Peregrinação "Esmola" nas casas dos devotos

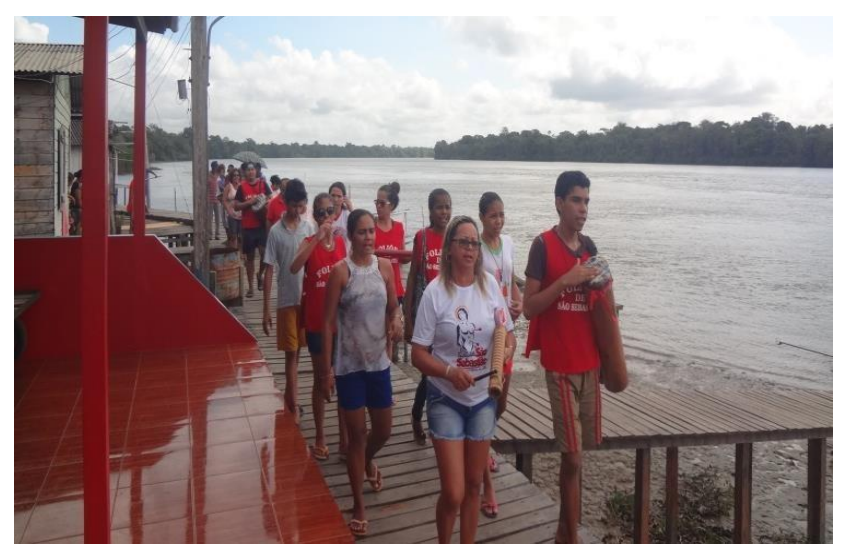

Fonte: Luã Alho (2016).

O termo "esmola” refere-se à peregrinação da imagem de São Sebastião às casas dos moradores, em diversas comunidades do rio Jari e do Rio Amazonas, que têm o referido Santo como intercessor. Movidos pela força da tradição, o cortejo religioso vai cantando hino, tocando os tambores, levando a bandeira e a imagem nas mãos, passando nas casas daqueles que aceitam recebê-los.

Chegando às casas dos devotos, reza-se o Pai-Nosso, Ave-Maria, Glória ao Pai e cantam-se vários cânticos (Hino de São Sebastião, Casa Santa, Levantaivos soldados de Cristo, entre outros. As famílias agradecem ao santo pelas graças recebidas por meio da oração e ofertando (não obrigatoriamente) algum donativo, como: porco, frango, pato, cacho de banana, boi, leite, dinheiro, entre outros. Todos os donativos são leiloados para angariar recursos para melhorar a cada ano o festejo. Depois de visitadas todas as comunidades, os foliões retornam da peregrinação um dia antes do início da festa. 
Figura 4 - Peregrinação "Esmola" nas casas dos devotos

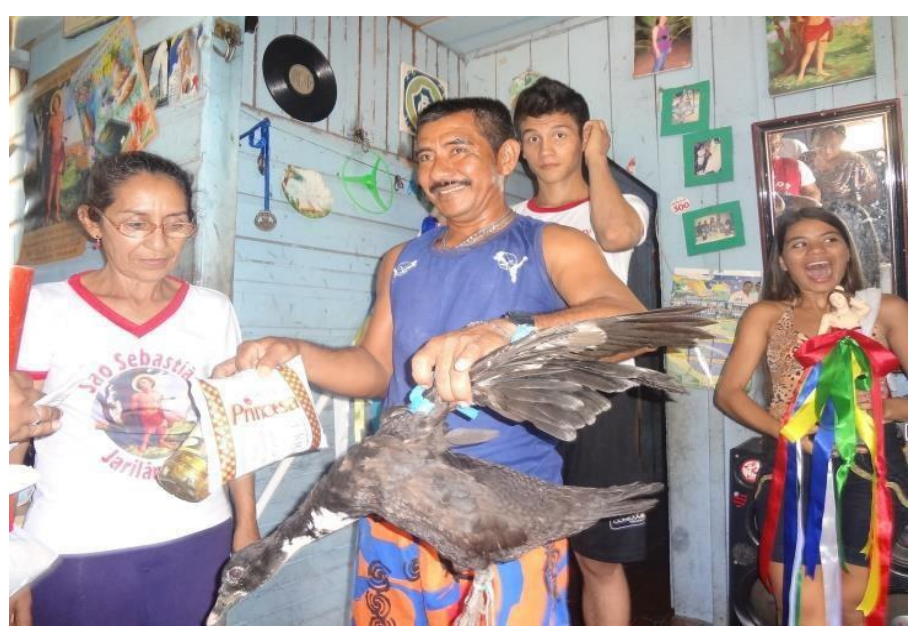

Fonte: Luã Alho (2013).

No dia 18, com a festa já iniciada, a equipe de foliões aumenta devido à chegada dos romeiros. A peregrinação é feita em Jarilândia. Inicia na Ponte do Bacabal, com um café da manhã na casa sede da família Góes. Tal procedimento estende-se até a última casa, localizada atrás da igreja.

\section{Abertura da festa}

No dia 10 de janeiro a abertura da festa começa com a alvorada - uma queima de fogos - , que é acesa às 5hoo, para anunciar que o festejo em honra a São Sebastião vai começar. Nesse momento a equipe de som do salão paroquial coloca músicas católicas para acolher as famílias e depois é feito um momento de boas-vindas e orações. Logo depois é servido o café da manhã, ofertado gratuitamente aos devotos. 
Figura 5 - Alvorada e café da manhã

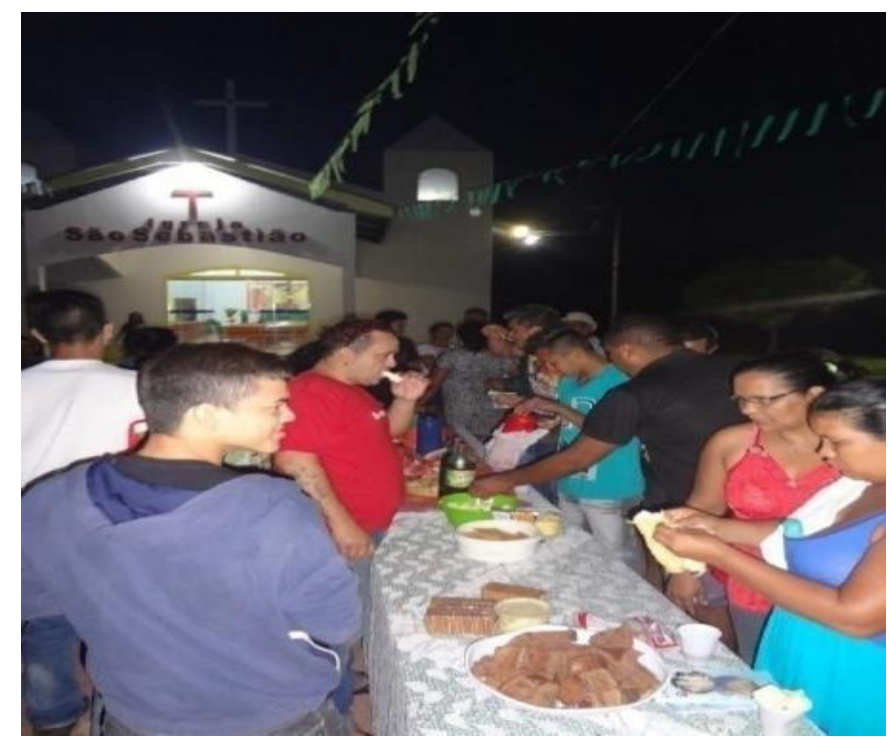

Fonte: Luã Alho (2016).

À tarde a comunidade prepara o mastro de frutas. Esse mastro é um esteio em madeira - preparado com antecedência pela equipe organizadora - e é revestido com folhas de açaizeiro. Nele as famílias colocam frutas cultivadas na região, ainda maduras, como: banana, mamão, cana e jerimum, para agradecer pela colheita. Bem no alto do mastro é colocado um cesto com castanha (produto cultivado desde a criação da Vila de Jarilândia). Mais em cima, é inserido a bandeira de São Sebastião.

Com tudo organizado, as famílias retornam para as casas, e às $17 \mathrm{~h} 30$ voltam à igreja para mais um ato da festa. No horário, todos se encaminham para a igreja. O dirigente da celebração dá as boas-vindas e encaminha os devotos para a área externa. Em procissão com o andor ${ }^{18}$ do padroeiro, cantamse hinos do padroeiro para o levantamento do mastro e da bandeira central.

\footnotetext{
18 Suporte de madeira, onde a imagem é posta, para ser transportada nas procissões.
} 
Figura 6 - Mastro

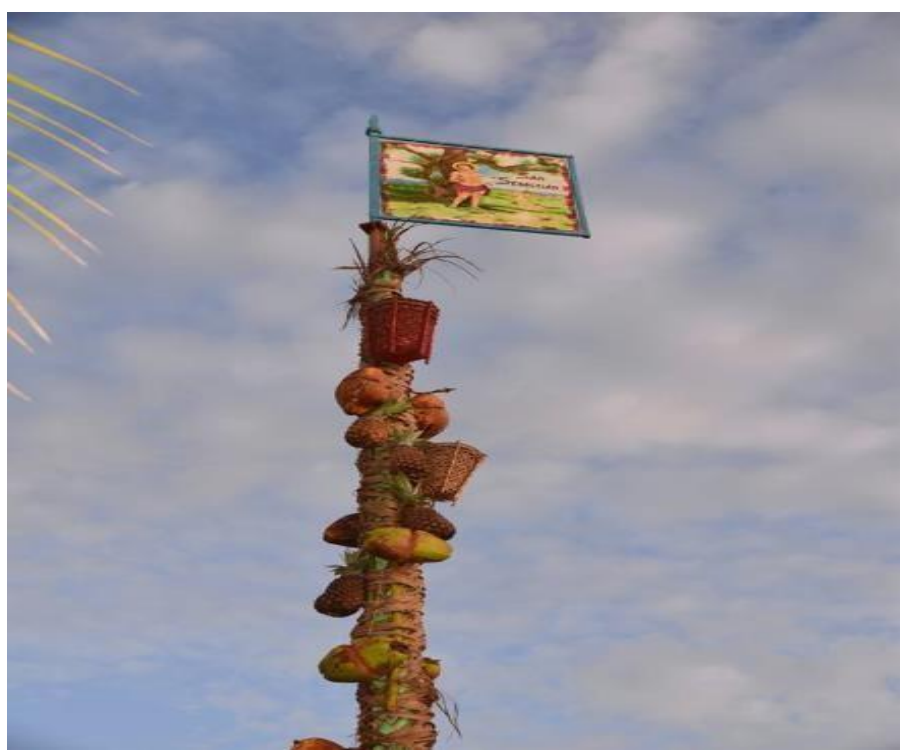

Fonte: Luzete Góes (2016).

O mastro de frutas é levantado junto com a Bandeira Central. Esta é erguida pelos Juízes da festa que se prontificaram no ano anterior em realizála. É suspenso no meio da praça e firmado sob nós bem difíceis de serem desatados, sob o significado de que quem conseguir desatar terá uma jornada bem trabalhosa a cumprir, assim como os nós que desatou.

Figura 7 - Levantamento da Bandeira Central

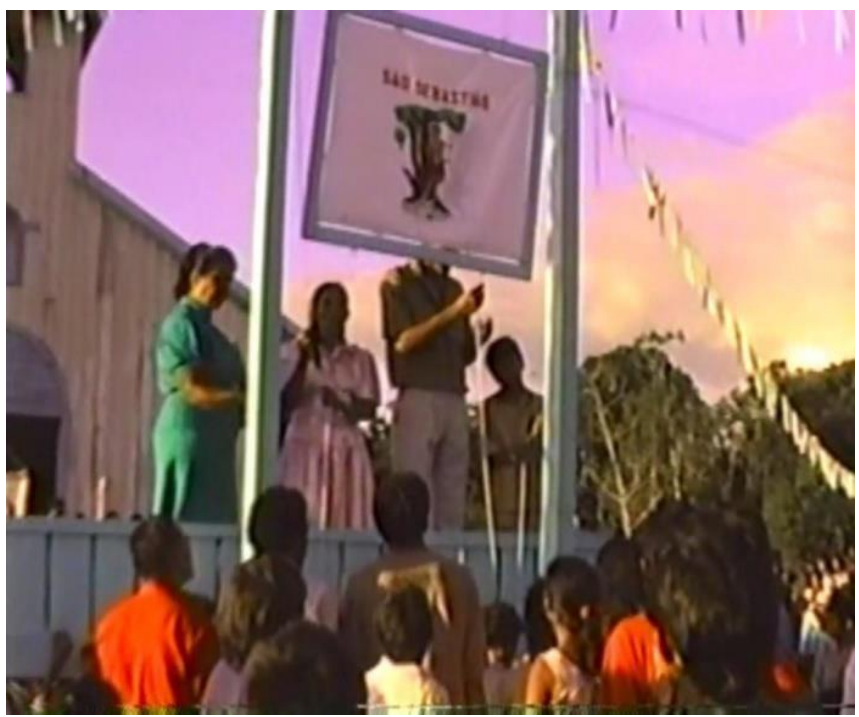

Fonte: Família Biluca (1991). 
À noite inicia-se o novenário, sob a responsabilidade das famílias que, em seus dias respectivos - chamados de noitários - desempenham as atribuições de: arrumar, enfeitar, cantar e fazer todo o rito religioso, que inclui a novena, a reza do terço, as leituras do Evangelho, a ladainha e outros cânticos. Isso se estende de 10 a 19 de janeiro. Ambos são necessários para o cumprimento da tradição da festa.

\section{Meia lua}

Na tarde do dia 18 de janeiro os devotos saem em procissão com a bandeira, a cruz, os estandartes de Jesus e Maria, os anjinhos (devotos mirins vestidos com roupa de anjos) e com o andor que leva a imagem do padroeiro rumo ao Porto localizado na frente da Vila. Nele, embarcações de grande e de pequeno porte aguardam os devotos para a realização da "Meia lua" de São Sebastião do Rio Jari.

O termo Meia lua ${ }^{19}$ é dado devido às três voltas que as embarcações dão em frente à Jarilândia. Essas voltas são dadas em um formato da metade de uma lua cheia. Na Meia lua, chamada também de procissão fluvial, os foliões de São Sebastião vão tocando e cantando, e junto com a equipe de liturgia vão rezando o terço. Dadas as três voltas, as embarcações atracam no porto e todos voltam para a igreja para a realização da novena.

Figura 8 - Meia Lua de São Sebastião

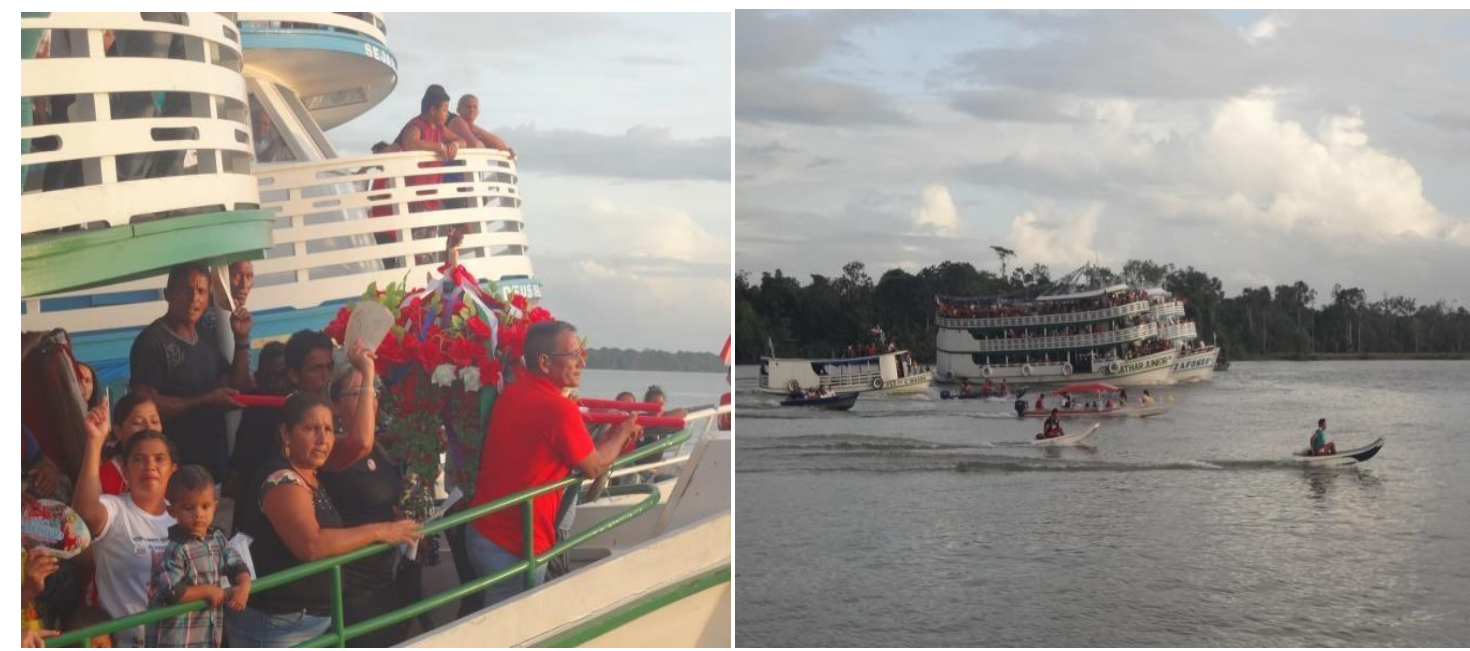

Fonte: Luéliton Alho (2016).

\footnotetext{
${ }^{19}$ Fonte: Izaneide Góes (40 anos). Técnica em enfermagem no município de Santana é devota e foliã do padroeiro. É uma das animadoras na peregrinação do dia 18 de janeiro. É filha de Iracilda Góes e Sebastião Tavares.
} 


\section{Procissão}

O último dia da festa é a grande procissão, com a presença do padre da Paróquia de Vitória do Jari. Para esse momento as mulheres novamente vestem seus filhos de anjinhos. À frente do cortejo religioso vai a bandeira do santo, abrindo passagem. Logo depois, o maior símbolo do catolicismo, a cruz; os estandartes de Jesus e Maria; a bíblia com as velas, e o santo carregado sobre os ombros dos devotos.

No ano do Centenário, 2016, foram feitas paradas em frente às casas de pessoas que faleceram e que contribuíram para os cem anos da festa. A comunidade homenageou essas pessoas com orações e pediram a proteção divina para essas famílias. Na chegada da procissão em frente à igreja, é feita à descida da bandeira central, em que os devotos que desamarrarem os nós dela serão os próximos organizadores da festa, isto é, os juízes.

Em seguida, o momento de disputa da festa, a derrubada do mastro, quando homens buscam pelos frutos colocados no mastro. $\mathrm{O}$ mais procurado é o cesto de castanha, pois quem alcança é visto como campeão. Isso porque a castanha é um símbolo histórico da Vila por seu cultivo datar da origem de Jarilândia; e por ser o prêmio de maior valor simbólico e quantidade no mastro. A bandeira do santo no mastro também é retirada. Pegar a bandeira é uma forma de agradecimento e de pedir a proteção para que possa voltar no próximo ano.

A festa religiosa termina com a celebração da missa, em que todos os devotos participam e celebram o dia de São Sebastião e o término de mais um ano do festejo. 
Foto 9 - Procissão

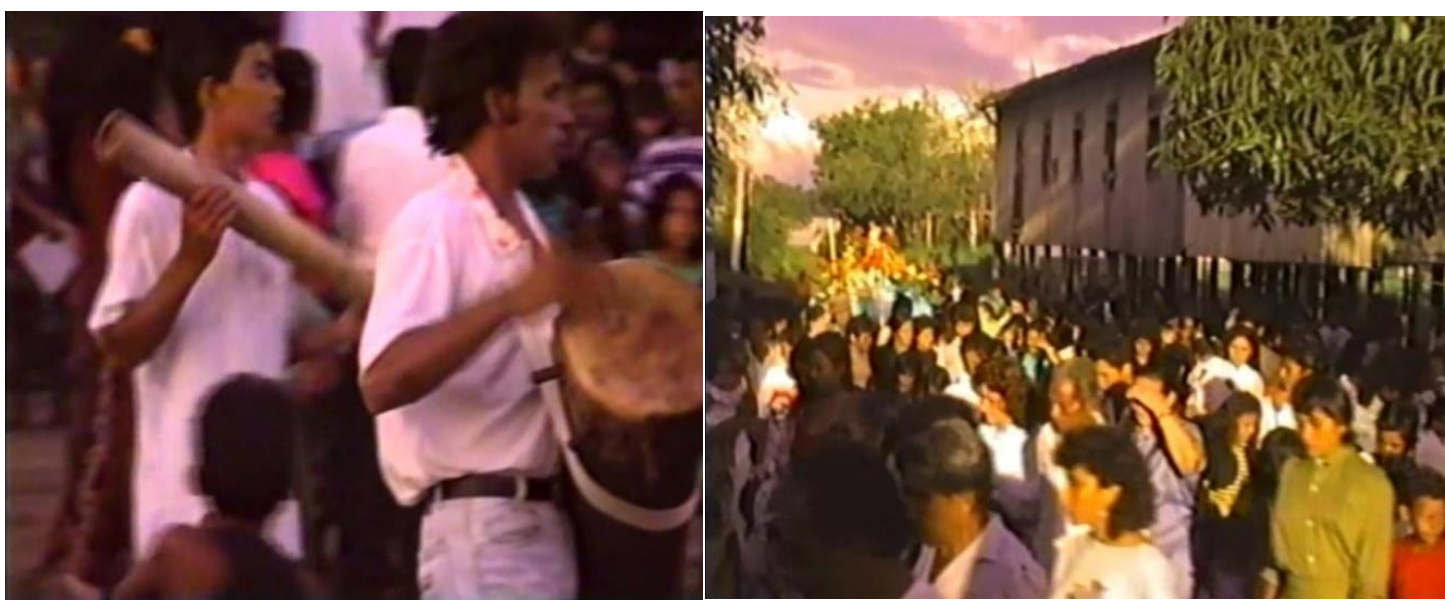

Fonte: Família Biluca (2015).

\section{A festa social}

Poucas vezes a vila de Jarilândia vai dormir tão tarde como ocorre no período de janeiro. As famílias, após o ato religioso, vão para casa, ou para o lugar onde estão alojadas, se arrumar para a festa dançante referente à festividade de São Sebastião.

Em Jarilândia, quatro casas de show celebram a festa social. A principal é o salão paroquial, onde as famílias e visitantes se confraternizam ao som de diversos ritmos, como bolero, forró, dance music e o carimbó (patrimônio cultural imaterial do Pará) que, devido à fronteira com o estado paraense, é apreciado pelos adultos, idosos e jovens que rodopiam no salão. Neste mesmo salão são realizados leilões (com as doações feitas no ato da esmola citado anteriormente) a fim de ajudar nas despesas da festa.

No dia 20 de janeiro, último dia da festa, é realizado o desfile e a escolha da Rainha e da Princesa de São Sebastião. Trata-se de um concurso, em que meninas de 5 a 15 anos são antecipadamente definidas por suas famílias a participar, representando as comunidades vizinhas à Jarilândia. Elas se produzem e são apadrinhadas por diversas pessoas, pois a definição do título é feita através da venda de votos, tudo em prol da festa e da comunidade paroquial. 
Figura 10 - Rainha e Princesa de São Sebastião

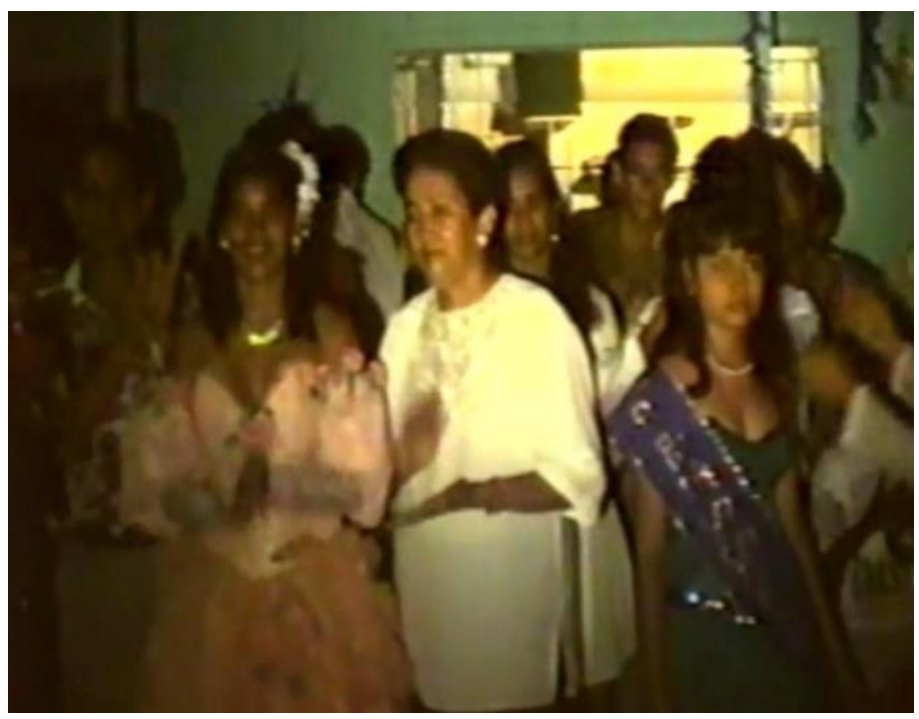

Fonte: Família Biluca (1995).

A candidata eleita ganha o título de Rainha dos Festejos de São Sebastião, se comprometendo a passar a faixa para a Rainha do ano vindouro. As demais meninas que concorreram ganham o título de Princesas. As Rainhas eleitas sentem grande emoção, conforme o depoimento da senhora Araguacy Tavares $^{20}$ (42 anos), que aos 13 anos ganhou o concurso, no ano de 1987:

A emoção continua, a ansiedade toma conta, fico apreensiva como se eu tivesse concorrendo ao título novamente. Em 2015 fiquei mais ansiosa porque era madrinha de uma candidata. Sinto-me muito gratificada por poder colaborar com esta festividade todos os anos louvando a Deus e ao meu santo de devoção.

\footnotetext{
${ }^{20}$ Devota que organiza e sempre ajuda na divulgação da Festa em Santana e Macapá. É animadora na esmola e ajuda na organização. É Filha de Maria Tavares e Raimundo Bueno.
} 
Figura 11 - Rainha do ano 2012 ao repassar a faixa para a do ano 2013

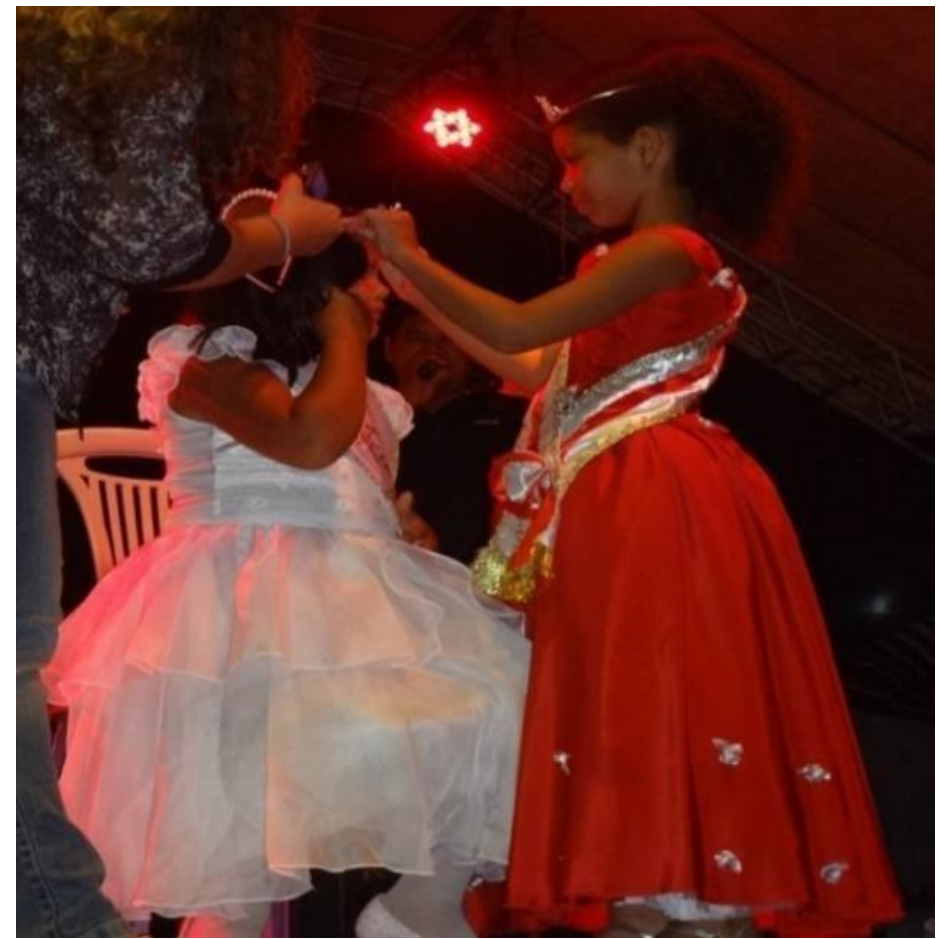

Fonte: Luã Alho (2015).

Já no Bar do Mirá e na danceteria Sete Estrelas, o som com DJ's animam a juventude. Durante o dia, o bar localizado às margens do rio Jari mantém a animação. Porém, durante os atos religiosos, o som precisa ser desligado em sinal de respeito às atividades do Festejo de São Sebastião. Na programação da festa social ainda é realizado o torneio de futebol masculino, quando o time de Jarilândia recebe adversários vindos de Laranjal e de Vitória do Jari.

\section{Considerações finais}

Com esta pesquisa, pudemos dar maior visibilidade à festa centenária de São Sebastião, fazendo deste trabalho uma conquista pessoal e acadêmicocientífica. Pessoal, porque envolve proximidade e apreço pela temática e pelo locus da pesquisa; e acadêmico-científica porque o contato nos permitiu conhecer, observar e analisar uma especificidade da cultura amapaense, a Festa de São Sebastião, evidenciado a importância de se trabalhar a cultura local no contexto da valorização do patrimônio cultural, tanto local quanto regional. 
Com os resultados da pesquisa, alcançamos os objetivos de identificar os elementos constitutivos desse festejo a partir dos relatos dos moradores mais velhos, onde estes foram e são muito importantes nesse processo de salvaguarda da cultura local de Jarilândia. A descrição dos elementos que constituem a festa nos possibilitou documentar os relatos pertinentes à cultura local, para que estes sirvam de base histórico-social de compreensão dos significados, incrementando a valorização, a salvaguarda e a promoção dessa festa.

Por fim, como fruto desta pesquisa, contribuímos para a inclusão da Festividade de São Sebastião de Jarilândia no calendário de eventos do estado do Amapá. Esse feito deu-se em parceria com o Deputado Jory Oeiras que propôs a seus pares na Câmara Municipal do Jari a aprovação do Projeto de Lei n 1939/2015, que visa promover a festa centenária de São Sebastião como festividade histórica e social fundamental para a construção e afirmação da identidade cultural do povo de Jarilândia no estado do Amapá.

\section{Referências}

BRASIL. Constituição (1988). Constituição da República Federativa do Brasil. Brasília, DF: Senado, 1988.

BRASIL. Instituto Brasileiro de Geografia e Estatística (IBGE). Censo Populacional 2010. Disponível em <https://www.ibge.gov.br/>. Acesso em: 11 nov. 2015.

BURKE, P. Hibridismo Cultural. São Leopoldo: Ed. Unisinos, 2006.

GEERTZ, C. A interpretação das culturas. Rio de janeiro: LTC, 2013.

HALL, S. A identidade cultural na pós-modernidade. 7. ed. Rio de Janeiro: DP\&A, 2002.

LARAIA, R. B. Cultura: Um conceito antropológico. 14. ed. Rio de Janeiro: Jorge Zahar, 2001.

MAUÉS, R. H.; VIEIRA, C. G. et al. (orgs.). Diversidade biológica da Amazônia. Belém: Museu Paraense Emílio Goeldi, 2001. p. 253-272.

OLIVEIRA, M. M. Como fazer pesquisa qualitativa. 2. ed. Petrópolis: Vozes, 2008.

VIDEIRA, P. L. Marabaixo dança afrodescendente: significando a identidade étnica do negro amapaense - Fortaleza: Edições UFC, 2009. 